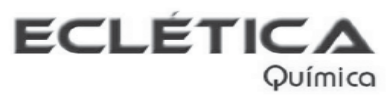

www.scielo.br/eq

Volume 29, número 2, 2004

\title{
Titulação amperométrica de compostos fenólicos usando polifenol oxidase de vegetal como titulante
}

\author{
I. C. Vieira*, O. Fatibello-Filho**, A. C. Granato**, K. O. Lupetti** \\ *Departamento de Química, Centro de Ciências Físicas e Matemáticas, \\ Universidade Federal de Santa Catarina, 88040-900, Florianópolis-SC. \\ ${ }^{* *}$ Departamento de Química, Centro de Ciências Exatas e de Tecnologia, \\ Universidade Federal de São Carlos, CP 676, 13560-970, São Carlos-SP.
}

\begin{abstract}
Resumo: Titulação amperométrica de compostos fenólicos usando extrato bruto de batata doce (Ipomoea batatas (L.) Lam.), fonte da enzima polifenol oxidase, como titulante é proposta para determinação de fenóis em águas residuárias. Esta enzima catalisa a oxidação de monofenol e difenol pelo oxigênio molecular produzindo o-quinona. Um eletrodo de oxigênio foi usado como eletrodo indicador e o consumo de oxigênio na solução foi proporcional à concentração do substrato (analito). Esse método apresentou uma resposta linear para catecol, pirogalol, hidroquinona, fenol e p-cresol na faixa de

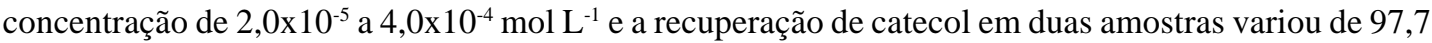
a 102\%. Os resultados obtidos para compostos fenólicos em águas residuárias de indústrias usando o procedimento proposto e o método padrão estão em concordância a um nível de confiança de 95\%.
\end{abstract}

Palavras-chave: Polifenol oxidase; enzima; composto fenólico; água residuária.

\section{Introdução}

Os compostos fenólicos estão presentes em efluentes de diversas indústrias e esgotos domésticos. Há necessidade do tratamento de efluentes que possuem esses compostos antes do lançamento no meio ambiente, uma vez que estes causam danos à fauna e a flora. São tóxicos aos peixes na concentração de 1 a $10 \mathrm{mg} \mathrm{L}^{-1}$, provocando cheiro e sabor desagradável à água. No Brasil o padrão de emissão de fenóis permitido é de $0,5 \mathrm{mg} \mathrm{L}^{-1}$ em rios e $5,0 \mathrm{mg} \mathrm{L}^{-1}$ em redes de esgotos. Os fenóis além de prejudicar a saúde são tóxicos ao homem na concentração de $13 \mathrm{mg} \mathrm{kg}^{-1}$ do peso corpóreo. No organismo é transformado em ácido fenilsulfúrico que é eliminado pela urina na forma de fenilsulfatos de alguns cátions de metais alcalinos. São voláteis e a concentração máxima permitida no ar[1-3] é de $5 \mathrm{mg} \mathrm{L}^{-1}$,
Existem vários procedimentos relatados na literatura para determinação de compostos fenólicos, entre eles, os espectrofotométricos[48]. O reagente 4-aminoantipirina é usado no método padrão[4] (Standard Methods for the Examination of Water and Wastewater) para determinação de compostos fenólicos em águas naturais, de abastecimento, residuárias e águas do mar. É também o método proposto pelas Normas Técnicas da Companhia de Tecnologia e Saneamento Básico - CETESB[5]. Nesse procedimento os compostos fenólicos voláteis são separados dos interferentes não voláteis por destilação, sendo em seguida determinados espectrofotometricamente empregando-se 4aminoantipirina em $510 \mathrm{~nm}$ (solução aquosa) ou em 460 nm (clorofórmio). 
Atualmente vários procedimentos para determinação de fenóis usando métodos enzimáticos vem sendo empregados[2,3,9-13]. Kuriama e Rechnitz[9] em 1981 construíram o primeiro biossensor de tecido vegetal. E desde então, tecido de diversos vegetais vem sendo usado na construção de biossensores para determinação de analitos de interesse farmacêutico, alimentício, ambiental e análises clínicas, uma vez que podem oferecer métodos simples, estáveis, seletivos e de baixo custo. Uchiyama et al.[10] desenvolveram um biossensor amperométrico seletivo a catecol utilizando folhas de espinafre (Spinacea oleracea) picadas e suportadas por uma membrana de diálise (Technicon “C”). Esse biossensor apresentou um tempo de resposta de 5-10 min (40 - $60 \mathrm{mg}$ de tecido) e uma linearidade de $2,0 \times 10^{-4}$ a $8,0 \times 10^{-4}$ mol L ${ }^{-1}$ de catecol. Botrè et al.[11] construíram um biossensor para catecol, usando uma fatia fina (espessura de $100 \mathrm{~mm}$ e diâmetro de $10 \mathrm{~mm}$ ) de tecido de batata (Solanum tuberosum) fixada com uma membrana de diálise diretamente em um eletrodo de oxigênio. A curva analítica obtida foi linear no intervalo de concentração de $2,5 \times 10^{-5} \mathrm{a}$ 2,3×10-4 $\mathrm{mol} \mathrm{L}^{-1}$ de catecol.

No entanto, são poucos os métodos enzimáticos relatados na literatura usando extrato bruto de tecidos vegetais. Apesar destes métodos, em alguns poucos casos, apresentarem baixa seletividade, possuem várias vantagens, entre elas, baixo custo, facilidade de execução dos procedimentos enzimáticos e principalmente a grande variedade e disponibilidade de material biológico vegetal.

O primeiro trabalho usando extrato bruto vegetal foi desenvolvido por Uchiyama et al.[12]. Estes pesquisadores determinaram dopamina, catecol e adrenalina usando extrato bruto de banana e espinafre (fonte da enzima polifenol oxidase) como reagente carregador em um sistema de análise de injeção em fluxo. Em seguida, Signori e Fatibello-Filho[13] desenvolveram um biossensor amperométrico imobilizando extrato bruto de inhame (Alocasia macrohiza) com glutaraldeído e albumina de soro bovino diretamente em uma membrana de um eletrodo de oxigênio. $\mathrm{O}$ biossensor apresentou respostas lineares para pirogalol, catecol, fenol e p-cresol nas faixas de concentração de $2,5 \times 10^{-5}$ a $8,0 \times 10^{-5}$ mol L-1, $1,0 \times 10^{-5}$ a $8,5 \times 10^{-5} \mathrm{~mol} \mathrm{~L}^{-1}, 1,0 \times 10^{-5}$ a $9,0 \times 10^{-5} \mathrm{~mol} \mathrm{~L}^{-1}$ e $1,0 \times 10^{-5}$ a $1,0 \times 10^{-4} \mathrm{~mol} \mathrm{~L}^{-1}$, respectivamente.

Além daqueles vegetais empregados na construção de biossensores, outros têm sido utilizados como fonte da enzima polifenol oxidase e peroxidase em diversos procedimentos analíticos[2,3,13-18].

A polifenol oxidase (E.C.1.10.3.1) é também chamada de tirosinase, fenolase, catecol oxidase, catecolase e creolase. Essa enzima catalisa tanto monofenóis (e.g. tirosina, fenol, p-cresol) como difenóis (catecol, L-dopa, dopamina, adrenalina). É largamente distribuída na natureza e encontrada em vários tecidos vegetais.

Nesse trabalho, um extrato bruto de batata doce (Ipomoea batatas (L.) Lam.), fonte da enzima polifenol oxidase, foi utilizado como titulante em uma titulação amperométrica de compostos fenólicos. Após otimização dos parâmetros investigados, essa metodologia foi utilizada para a determinação de compostos fenólicos em águas residuárias de indústrias.

\section{Parte experimental}

\section{Equipamentos}

O extrato bruto da batata doce (Ipomoea batatas (L.) Lam), fonte da enzima polifenol oxidase, foi homogeneizado em um liquidificador Firenze da Walita RI6755 e o homogenato foi centrifugado em uma centrifuga Du Pont Instruments Sorval modelo RC-5B, provida de rotor modelo SS-34 com diâmetro de $23 \mathrm{~cm}$.

As medidas espectrofotométricas para determinação de proteína total e atividade foram feitas em um espectrofotômetro Femto, modelo 435, com uma célula de quartzo (caminho óptico $1,00 \mathrm{~cm}$ ) conectado a um registrador Cole Parmer (Niles, IL, USA, modelo 12020000 de dois canais). O efeito da temperatura na reação enzimática foi feito usando-se um banho termostático Tecnal, modelo TE 184.

As medidas amperométricas foram feitas em uma célula de vidro termostatizada a $25,0 \pm 0,2^{\circ} \mathrm{C}$, sob agitação constante, empregandose um eletrodo de oxigênio tipo Clark, modelo 203A acoplado a um analisador de oxigênio da FAC modelo 204A (São Carlos/SP). Esse eletrodo 
contendo um cátodo de platina e um ânodo de Ag/ $\mathrm{AgCl}$ foi polarizado em um potencial constante de $-600 \mathrm{mV}$. Foi previamente calibrado em $0 \%$ de oxigênio com uma solução saturada de bissulfito de sódio (Carlo Erba) e em 100\% de oxigênio com uma solução saturada de oxigênio.

As medidas de $\mathrm{pH}$ das soluções foram feitas utilizando um pHmetro Orion modelo EA 940, com precisão de 0,1 mV (ou 0,001 unidades de $\mathrm{pH}$ ) contendo um eletrodo de vidro Ingold, modelo 10/402/3092.

Reagentes e soluções

Fenol, catecol, pirogalol, hidroquinona, o-cresol, m-cresol e p-cresol reagentes de grau analítico foram adquiridos da Sigma Chemical Co (St. Louis, MO, USA), e utilizados para preparação das soluções de referência. As soluções usadas para construção da curva analítica e determinação da atividade enzimática da polifenol oxidase foram preparadas recentemente. A água empregada na preparação das soluções foi proveniente de um sistema Milli-Q Millipore (Redford, MA, USA, modelo UV Plus Ultra-baixo teor de compostos orgânicos dissolvidos).

Foram preparadas soluções tampão acetato (pH 5,0 e 5,5), fosfato $(6,0,6,5$ e 7,0) e borato $(7,5$ e 8,0$)$ na concentração de $0,1 \mathrm{~mol} \mathrm{~L}^{-1}$, empregando-se reagentes da Merck.

A solução interna do eletrodo de oxigênio foi preparada a partir das soluções de dihidrogêniofosfato de sódio (Merck) 0,15 mol L${ }^{1}$, cloreto de potássio (Merck) 0,3 mol L ${ }^{-1}$ e solução de hidróxido de sódio (Merck) 3,0 mol L-1 gotejada lentamente até pH 12.

Obtenção do extrato bruto e determinação da atividade enzimática

A polifenol oxidase utilizada para desenvolvimento desse trabalho foi obtida de tecido da batata doce (Ipomoea batatas (L.) Lam). Após a lavagem, secagem, pesou-se $25 \mathrm{~g}$ deste vegetal descascado e homogeneizou-se em um liquidificador com $100 \mathrm{~mL}$ de tampão fosfato 0,1 mol L-1 (pH 7,0), contendo 2,5 g de agente protetor (Polyclar SB-100). O homogenato foi filtrado em quatro camadas de gazes e centrifugado a 25.000xg (18.000 r.p.m.) durante $10 \mathrm{~min}$, a $4^{\circ} \mathrm{C}$. Em seguida, o sobrenadante foi dividido em diversas alíquotas de $10 \mathrm{~mL}$, armazenadas em refrigerador a $4^{\circ} \mathrm{C}$ e usados como fonte da enzima polifenol oxidase.

A atividade dessa enzima presente no tecido vegetal da batata doce foi determinada pela medida de absorbância em 420 nm durante 3 min da o-quinona formada após a reação entre $0,2 \mathrm{~mL}$ da solução sobrenadante enzimática e $2,8 \mathrm{~mL}$ da solução de catecol $0,05 \mathrm{~mol} \mathrm{~L}^{-1}$ em tampão fosfato $0,1 \mathrm{~mol} \mathrm{~L}^{-1}(\mathrm{pH} 7,0)$ a $25^{\circ} \mathrm{C}$.

\section{Procedimento experimental}

O eletrodo de oxigênio tipo Clark possui uma membrana de Teflon permeável ao oxigênio que separa o eletrólito interno e os eletrodos (cátodo e ânodo) do meio externo. O eletrodo foi colocado em uma célula de vidro termostatizada à $25^{\circ} \mathrm{C}$ contendo $10 \mathrm{~mL}$ do substrato fenólico em tampão fosfato $0,1 \mathrm{~mol} / \mathrm{L}(\mathrm{pH} \mathrm{7,0)}$. Após a estabilização da leitura, adicionaram-se volumes crescentes ( 0 a 5,0 $\mathrm{mL}$ ) do extrato bruto da batata doce em tampão fosfato $0,1 \mathrm{~mol} \mathrm{~L}^{-1}(\mathrm{pH} 7,0)$ contendo 35 unidades $\mathrm{mL}^{-1}$ de $\mathrm{PFO}$, determinada anteriormente, em intervalos de tempo de 1 minuto entre cada adição, com agitação e temperatura constante.

Adições sucessivas da enzima PFO causam uma diminuição da concentração de oxigênio do meio reacional. No tratamento dos dados para a construção das curvas analíticas foram feitas correções para as diluições efetuadas, [(Vo+Va)/ Vo], onde Vo representa o volume inicial da solução do substrato e Va o volume da solução da enzima adicionada. $\mathrm{O}$ mesmo procedimento foi realizado para a determinação de compostos fenólicos em águas residuárias.

\section{Resultados e discussão}

Reação enzimática e o eletrodo de oxigênio

A polifenol oxidase catalisa a oxidação de fenol pelo oxigênio molecular dissolvido produzindo 1,2-benzenodiol e a oxidação deste produto produz a o-quinona, como é mostrado na Figura 1. Assim, a adição sucessiva do volume de titulante (extrato bruto contendo a PFO) na solução contendo os substratos fenólicos (titulado) causa uma diminuição da concentração de oxigênio $\left(\% \mathrm{O}_{2}\right)$. 
O eletrodo para oxigênio possui uma membrana de Teflon que separa o eletrólito interno e os eletrodos (cátodo e ânodo) do meio externo, como mostra a Figura 2. A membrana é permeável ao oxigênio que se difunde até o cátodo de platina reduzindo-se num processo redox envolvendo 4 elétrons, gerando assim uma corrente proporcional à concentração de oxigênio no meio reacional. Assim, quanto maior for à concentração do substrato na solução a ser analisada (ou solução padrão) maior será a diminuição da concentração de $\mathrm{O}_{2}$. O sensor opera da maneira mostrada na Equação 1.

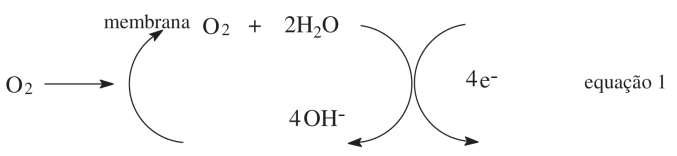

O eletrodo de referência de $\mathrm{Ag} / \mathrm{AgCl}$ funciona também como contra-eletrodo (ânodo) e a reação de oxidação: $\mathrm{Ag}^{\circ}+\mathrm{Cl}^{-} \mathrm{D} \mathrm{AgCl}+\mathrm{e}^{-}$, ocorre quando um potencial de polarização constante de - $600 \mathrm{mV}$ é aplicado no sensor amperométrico. Assim, a corrente monitorada entre os eletrodos é proporcional à concentração de oxigênio dissolvido na solução.
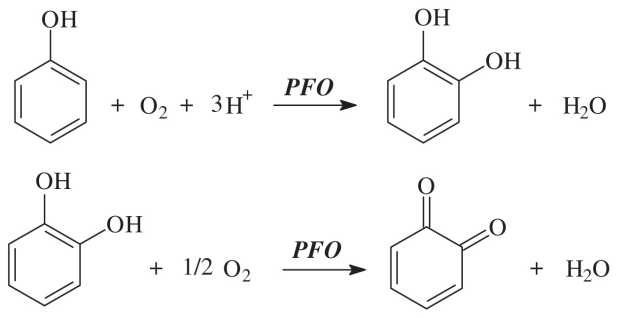

FIGURA 1- Reação de oxidação catalítica do fenol
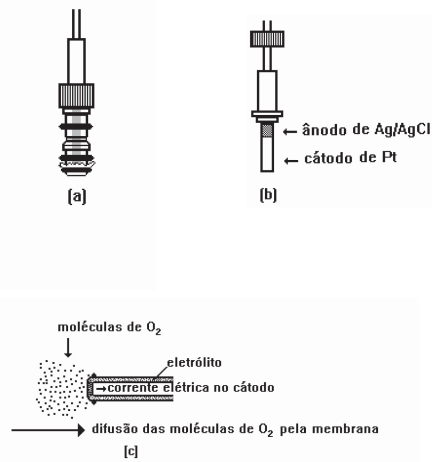

FIGURA 2 - Esquema do (a) eletrodo de oxigênio, (b) cátodo e ânodo e (c) difusão de oxigênio pela membrana.
Efeito da concentração da polifenol oxidase

$O$ efeito da concentração da enzima polifenol oxidase de 12 a 55 unidades sobre a resposta amperométrica do eletrodo de oxigênio foi inicialmente estudado. Houve um aumento da resposta amperométrica de 12 a 23 unidades de PFO $\mathrm{mL}^{-1}$ mantendo-se constante em concentrações superiores, como pode ser observado na Figura 3. Para o desenvolvimento deste trabalho, foram empregadas 35 unidades da enzima PFO $\mathrm{mL}^{-1}$ como titulante para determinação de compostos fenólicos.

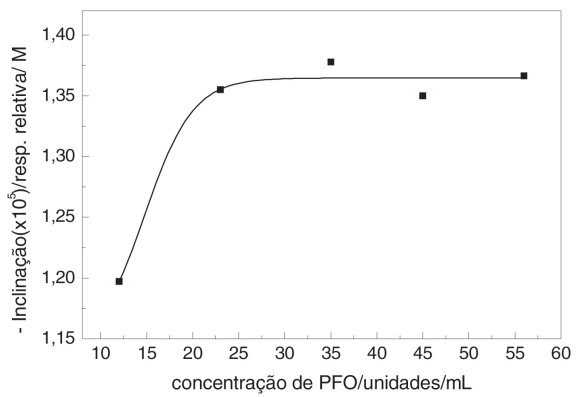

FIGURA 3 - Estudo da concentração da enzima polifenol oxidase de 12 a 55 unidades $\mathrm{mL}^{-1}$ sobre a resposta

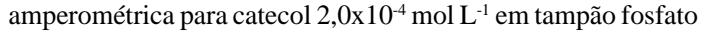
$0,1 \mathrm{~mol} \mathrm{~L}^{-1}(\mathrm{pH} \mathrm{7,0)}$.

Efeito do $\mathrm{pH}$

O efeito do $\mathrm{pH}$ variando de 5 a 8 sobre a resposta amperométrica do eletrodo de oxigênio na titulação de catecol $2,0 \times 10^{-4} \mathrm{~mol} \mathrm{~L}^{-1}$ com extrato bruto da batata doce contendo 35 unidades $\mathrm{mL}^{-1}$ de PFO é mostrado na Figura 4. A melhor resposta foi verificada em $\mathrm{pH} 7,0$. Sendo assim, escolheuse solução tampão fosfato $\mathrm{pH} 7,0$ para o desenvolvimento desse trabalho.

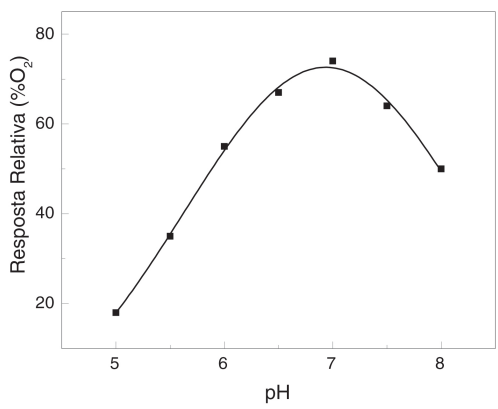

FIGURA 4 - Estudo do efeito do pH de 5,0 a 8,0 na titulação

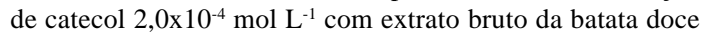
contendo 35 unidades de PFO $\mathrm{mL}^{-1}$ 


\section{Estudo do substrato fenólico}

As curvas analíticas para alguns substratos fenólicos (catecol, pirogalol, hidroquinona, fenol, o-cresol, m-cresol e p-cresol) foram determinadas usando-se o mesmo procedimento anterior. A Tabela 1 apresenta os valores das respostas relativas (\%) e a linearidade para alguns substratos fenólicos, usando-se 35 unidades da enzima polifenol oxidase $\mathrm{mL}^{-1}$ como titulante em tampão fosfato $0,1 \mathrm{~mol} \mathrm{~L}^{-1}(\mathrm{pH} 7,0)$ à $25{ }^{\circ} \mathrm{C}$. Pode-se observar que houve resposta relativa (\%) decrescente do catecol, pirogalol, hidroquinona, fenol e p-cresol no intervalo linear de concentração de $4,0 \times 10^{-5}$ a $2,0 \times 10^{-4} \mathrm{~mol} \mathrm{~L}^{-1}$, não apresentando respostas para o-cresol e mcresol. O valor das respostas relativas (\%) foi calculado em relação à resposta de catecol em $100 \%$.

O efeito dos substituintes do anel aromático influi na atividade enzimática, portanto o radical e a localização dos substituintes no anel levam a uma maior ou menor interação enzimasubstrato. No caso das polifenóis, agrupamentos $\mathrm{OH} o$ - e $p$-substituídos levam a uma maior resposta relativa do que agrupamentos $-\mathrm{CH}_{3}$. Assim, catecol e hidroquinona ( $o$ - e $p$-fenóis) são substratos que apresentam alta afinidade pela enzima se comparados com os cresóis ou mesmo o fenol, apresentando respostas mais elevadas.

\begin{tabular}{|c|c|c|}
\hline Substrato & Resposta relativa (\%) & Linearidade $\left(\times 10^{4} \mathrm{~mol} \mathrm{~L}^{-1}\right)$ \\
\hline Catecol & 100,0 & $0,4-3,0$ \\
\hline Pirogalol & 78,2 & $0,4-3,0$ \\
\hline Hidroquinona & 56,5 & $0,4-2,0$ \\
\hline Fenol & 21,6 & $0,4-2,0$ \\
\hline p-Cresol & 8,0 & $0,4-2,0$ \\
\hline m-Cresol & 0,0 & 0,0 \\
\hline o-Cresol & 0,0 & 0,0 \\
\hline
\end{tabular}

Tabela 1- Respostas relativas e linearidades obtidas na titulação de diversos substratos fenólicos empregando-se extrato bruto da batata doce (Ipomoea batatas (L.) Lam.) em tampão fosfato $0,1 \mathrm{~mol} \mathrm{~L}^{-1}(\mathrm{pH} 7,0)$ como titulante, a $25^{\circ} \mathrm{C}$.

\section{Estudo da repetibilidade}

Para o estudo da repetibilidade do método amperométrico proposto foram feitas seis determinações. Uma alíquota de $10,0 \mathrm{~mL}$ de catecol 8,0x10-5 $\mathrm{mol} \mathrm{L}^{-1}$ em tampão fosfato $0,1 \mathrm{~mol}$ $\mathrm{L}^{-1}(\mathrm{pH} 7,0)$ à $25^{\circ} \mathrm{C}$ foi titulada com 35 unidades da enzima polifenol oxidase $\mathrm{mL}^{-1}$ da batata doce em tampão fosfato $0,1 \mathrm{~mol} \mathrm{~L}^{-1}, \mathrm{pH}$ 7,0. A média de seis replicatas de percentagem de oxigênio corrigido foi de 46,9 $\pm 0,5$ com um coeficiente de variação de $1,02 \%$ demonstrando assim que o método desenvolvido apresenta boa repetibilidade.

\section{Curva analítica}

A Figura 5 reúne as curvas analíticas típicas obtidas na titulação amperométrica do substrato catecol usando-se como titulante 35 unidades da enzima Polifenol oxidase $\mathrm{mL}^{-1}$ (extrato bruto da batata doce) em tampão fosfato $0,1 \mathrm{~mol} / \mathrm{L}(\mathrm{pH} 7,0)$ à $25^{\circ} \mathrm{C}$.

Como pode ser observado, há um decréscimo da concentração de oxigênio a medida que o titulante é adicionado até atingir um valor constante de $\% \mathrm{O}_{2}$, onde todo o catecol reagiu produzindo o-quinona. Titulando-se diversas soluções de catecol em um intervalo de concentração de $2,0 \times 10^{-5}$ a $4,0 \times 10^{-4} \mathrm{~mol} \mathrm{~L}^{-1}$, foi possível construir uma curva analítica (Figura 6) relacionando a concentração de $\mathrm{O}_{2}$ (\% de oxigênio) em função da concentração da solução de catecol.

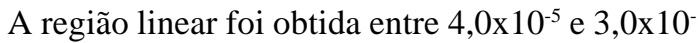
${ }^{4} \mathrm{~mol} \mathrm{~L}{ }^{-1}$ com $\mathrm{LD}=1,2 \times 10^{-5} \mathrm{~mol} \mathrm{~L}^{-1}$ e a equação da reta: $A=50,9-4,16 \times 10^{4}$ [catecol], onde $A=\%$ de oxigênio e [catecol] = a concentração de catecol em mol L-1.

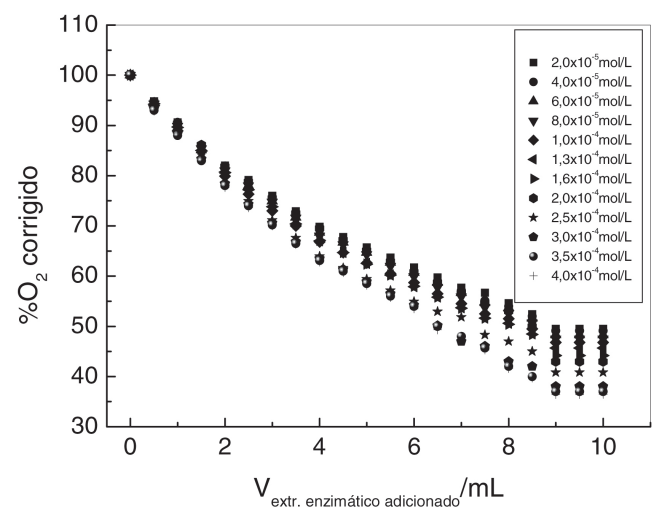

FIGURA 5 - Curvas típicas da titulação amperométrica de catecol em diversas concentrações com extrato bruto da batata doce (Ipomoea batatas (L.) Lam.) contendo 35 unidades de PFO $\mathrm{mL}^{-1}$ em tampão fosfato $0,1 \mathrm{~mol} \mathrm{~L}^{-1}, \mathrm{pH}$ 7,0 à $25^{\circ} \mathrm{C}$. 


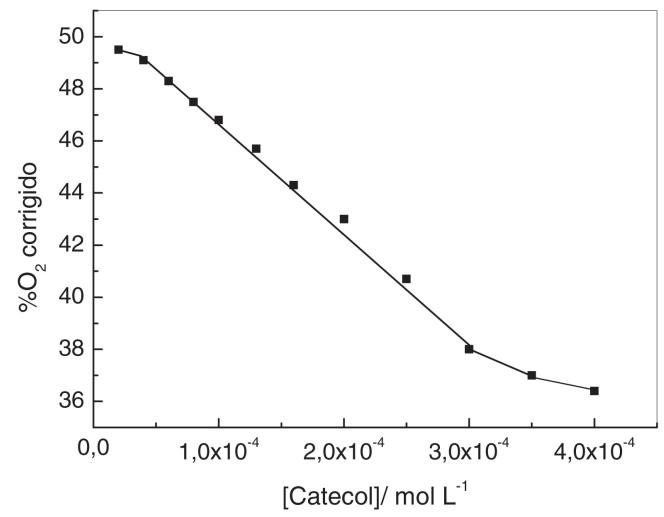

FIGURA 6 - Curva analítica obtida do catecol em tampão fosfato $0,1 \mathrm{~mol} \mathrm{~L}^{-1}(\mathrm{pH} \mathrm{7,0)}$.

Estudo de recuperação e determinação de fenóis em água residuária

Os fenóis estão presentes nos efluentes de diversas indústrias (e.g., tintas, vernizes, resinas, plásticos, farmacêuticas, couro e outras) e também em esgoto doméstico. São considerados como um dos resíduos orgânicos de maior toxicidade, sendo assim a sua determinação e/ou monitoramento é de extrema importância.

Os dados obtidos no estudo de adição e recuperação de catecol em águas residuárias de indústrias são apresentados na Tabela 2. Nesse estudo foram adicionados 8,8; 16,5 e 22,0 mg/L de catecol nestas amostras, obtendo-se uma percentagem de recuperação variando de 97,7 a 102 \%, indicando assim ausência de interferência da matriz sobre o método proposto.

Para avaliar o desempenho do método amperométrico proposto (titulação amperométrica), determinou-se a concentração de compostos fenólicos em águas residuárias de indústrias e para testar a validade do método desenvolvido, utilizou-se um método espectrofotométrico de absorção molecular oficial[4]. Os resultados obtidos estão apresentados na Tabela 3.

\begin{tabular}{|c|c|c|c|}
\hline \multirow{2}{*}{ Amostra } & \multicolumn{2}{|c|}{ Catecol $\left(\mathrm{mg} \mathrm{L}^{-1}\right)$} & Recuperação (\%) \\
\cline { 2 - 3 } & Adicionado & Recuperado & \\
\hline \multirow{3}{*}{ A } & 8,8 & 8,6 & 97,7 \\
& 16,5 & 16,2 & 98,2 \\
& 22,0 & 22,3 & 101 \\
& 8,8 & & 98,8 \\
& 16,5 & 16,6 & 101 \\
B & 22,0 & 22,5 & 102 \\
\hline
\end{tabular}

Tabela 2 - Estudo de adição e recuperação de catecol em águas residúarias

\begin{tabular}{|c|c|c|c|c|}
\hline \multirow{2}{*}{ Amostras } & \multicolumn{2}{|c|}{ Fenóis $\left(\mathrm{mg} \mathrm{L}^{-1}\right)^{\star}$} & $\begin{array}{c}\text { Erro } \\
\text { relativo }\end{array}$ & $\begin{array}{c}\text { Coeficiente } \\
\text { de variação }\end{array}$ \\
\hline & Espectrofotométrico & Amperométrico & $(\%)$ & \\
\hline A & $12,1 \pm 0,2$ & $11,2 \pm 0,2$ & $-7,4$ & 1,9 \\
\hline B & $24,8 \pm 0,4$ & $23,4 \pm 0,3$ & $-5,6$ & 1,2 \\
\hline C & $31,0 \pm 0,3$ & $32,1 \pm 0,3$ & $+3,5$ & 0,90 \\
\hline
\end{tabular}

Tabela 3 - Determinação de compostos fenólicos em águas residuárias de indústrias por espectrofotometria ${ }^{4}$ e pelo método amperométrico proposto. 


\section{Conclusões}

O tecido da batata doce (Ipomoea batatas (L.) Lam.) é rico de enzima polifenol oxidase e vêm sendo usado com sucesso pelos grupos de química analítica da UFSCar e UFSC no desenvolvimento de diversos procedim entos analíticos. A metodologia proposta pode ser utilizada como método alternativo por apresentar entre outras vantagens, boa precisão, simplicidade, rapidez e baixo custo.

\section{Agradecimentos}

Os autores agradecem à FAPESP, CNPq, UFSCar e UFSC.

Recebido em 18/02/04

Aceito em 22/04/04

I. C. Vieira, O. Fatibello-Filho, A. C. Granato. Amperometric titration of phenolic compounds using crude extract of sweet potato as titrant.

\begin{abstract}
Amperometric titration of phenolic compounds using crude extract of sweet potato (Ipomoea batatas (L.) Lam.) as enzymatic source of polyphenol oxidase and titrant is proposed for determining phenols in wastewaters. This enzyme catalyses the oxidation of monophenol and diphenols by molecular oxygen producing o-quinone. The oxygen electrode was used as indicator electrode and the consumption of $\mathrm{O}_{2}$ in the solution was proportionally to the substrate concentration. This method provides a linear response for catechol, pyrogallol, hydroquinone, phenol and p-cresol in the concentration range of $2,0 \times 10^{-5}$ a $4,0 \times 10^{-4} \mathrm{~mol} \mathrm{~L}^{-1}$ and the recovery of catechol from two samples ranged from 97.7 to $102 \%$. The results obtained for phenolic compounds in industrial wastewaters using the proposed procedure and those obtained using a standard method are in agreement at the $95 \%$ confidence level.
\end{abstract}

Keywords: polyphenol oxidase; enzyme; phenolic compound; wastewater.

\title{
Referências
}

[1] S. E. Manahan, Fundamentals of Enviromental Chemistry. Lewis publishers, Tokyo, 1993.

[2] I. C.Vieira, O. Fatibello-Filho, Anal. Lett. 30 (1997) 895.

[3] I. C.Vieira, O. Fatibello-Filho, Anal. Chim. Acta 366 (1998)111.

[4] A. D. Eaton, L. S. Clesceri, A. E. Greenberg, Standard methods for the examination of water and wasterwater. American Public Health Association, American Water Works Association and Water Environment Federation, Washington, 19.ed, 1995, p.5-36.

[5] Companhia Estadual de Tecnologia e Saneamento Básico (CETESB). Determinação de fenóis em águas - método colorimétrico da 4aminoantipirina. São Paulo. 1990. 125p.

[6] E. F Mohler, L. N Jacob, Anal. Chem. 29 (1957) 1369.
[7] J. Möller, M.Martin, Fres. J. Anal. Chem. 329 (1988) 728.

[8] K. D. Khalaf, B. A. Hasan, A. Morales-Rubio, M. La-Guardia, Talanta 29 (1982) 917.

[9] S. Kuriyama, G. A. Rechnitz, Anal. Chim. Acta 131 (1981) 91.

[10] S. Uchiyama, M. Tamata, Y. Tofuku, S. Suzuki, Anal. Chim. Acta 208 (1988) 287.

[11] F. Botrè, F. Mazzei, M. Lanzi, G. Lorenti, C. Botrè, Anal. Chim. Acta 255 (1991) 59.

[12] S. Uchiyama, Y. Tofuku, S. Suzuki, Anal. Chim. Acta 208 (1988) 291.

[13] C. A. Signori, O. Fatibello-Filho, Quím. Nova 17 (1994) 38.

[14] I. C. Vieira, O. Fatibello-Filho, Anal. Chim. Acta 366 (1998) 287.

[15] I. C. Vieira, O. Fatibello-Filho, Analyst 123 (1998) 1809. 
[16] I. C. Vieira, O. Fatibello-Filho, L. Angnes, Anal. Chim. Acta 398 (1999) 145.

[17] C. S. Caruso, I. C. Vieira, O. Fatibello-Filho, Anal. Lett. 32 (1999) 39.

[18] O. Fatibello-Filho, I. C. Vieira, J. Braz. Chem.

Soc.11 (2000) 412.
[19] M. Dixon, E.C. Webb, Enzymes, Academic press, New York,1979.

[20] J.R. Whitaker, Principles of enzymology for the food science, Marcel Dekker, New York,1972. 